Ciência Agrícola, Rio Largo, v. 16, n. 1, p. 1-9, 2018

\title{
CARACTERÍSTICAS AGRONÔMICAS DE CAPIM-CORRENTE (Urochloa mosambicensis) ADUBADO COM ESTERCO SUÍNO E SUBMETIDO A DUAS ALTURAS DE CORTE
}

\author{
Eduardo Henrique Sá Júnior ${ }^{1}$, Manoela Gomes da Cruz¹, Maurício Luiz de Mello Vieira Leite ${ }^{* 2}$, Leandro \\ Ricardo Rodrigues de Lucena ${ }^{2}$
}

\begin{abstract}
1'Discente de Graduação em Agronomia, Universidade Federal Rural de Pernambuco, , Unidade Acadêmica de Serra Talhada, Serra Talhada-PE

${ }^{2}$ Professor Adjunto, Universidade Federal Rural de Pernambuco, Unidade Acadêmica de Serra Talhada, Serra Talhada-PE
\end{abstract}

*Autor para correspondência: Maurício Luiz de Mello Vieira Leite, nopalea21@yahoo.com.br

\begin{abstract}
RESUMO: O capim-corrente (Urochloa mosambicensis Hack. Dandy) apresenta-se como uma espécie promissora para as regiões semiáridas devido as suas características de tolerância ao déficit hídrico e adaptação ao clima quente. Objetivou-se avaliar as características estruturais, índice de folhosidade, constituintes morfológicos e taxa de acúmulo de fitomassa do capim-corrente, adubado com esterco suíno e submetido a duas alturas de corte. Foram utilizadas quatro doses de adubação orgânica $\left(0,5,10\right.$ e 15 t.ha- $\left.^{-1}\right)$ e duas alturas de corte $(10$ e $20 \mathrm{~cm})$ com três repetições, sendo avaliados a taxa de acúmulo de fitomassa em três ciclos produtivos consecutivos, características estruturais e índice de folhosidade no final do primeiro ciclo e constituintes morfológicos no terceiro ciclo produtivo do capim-corrente. 0 acúmulo de fitomassa apresentou resposta linear crescente com relação ao aumento das doses de esterco suíno, sendo a altura de corte de $10 \mathrm{~cm}$ responsável por maior produtividade de matéria seca, assim como, a taxa de acúmulo de fitomassa foi crescente para o aumento das doses de esterco suíno, com altura de corte de $10 \mathrm{~cm}$ apresentando maiores valores. As características estruturais, índice de folhosidade e componentes morfológicos não apresentaram diferenças significativas para as condições testadas neste trabalho. Assim, constata-se a importância da adubação orgânica nas pastagens de regiões semiáridas, constituindo-se um meio para aumentar a produtividade de gramíneas adaptadas ao clima, fortalecendo a pecuária e reduzindo custos.
\end{abstract}

PALAVRAS-CHAVE: Adubação orgânica, Forragem, Gramínea xerófila, Semiárido.

\section{AGRONOMIC CHARACTERISTICS OF Urochloa mosambicensis FERTILIZED WITH SWINE PIG AND SUBMITTED TO TWO CUTTING HEIGHTS}

\begin{abstract}
The grass urocloa (Urochloa mosambicensis Hack. Dandy) is a promising species for semi-arid regions due to its characteristics of tolerance to water deficit and adaptation to hot weather. The objective of this study was to evaluate the structural characteristics, leaf index, phytomass accumulation, morphological constituents and rate of phytomass accumulation of this species, fertilized with swine manure and submitted to two cutting heights. Four doses were used of organic fertilization $\left(0,5,10,15\right.$ t.ha- $\left.^{-1}\right)$ and two cutting heights $(10$ e $20 \mathrm{~cm})$ with three replicates, being evaluated the accumulation of phytomass in the first productive cycle, the rate of phytomass accumulation in three consecutive productive cycles, structural characteristics and leaf index in the end of the first cycle and morphological constituents in the third productive cycle of the sabi grass. The phytomass accumulation showed an growing linear response in relation to the rise in the doses of swine manure, being the cutting height of $10 \mathrm{~cm}$ responsible for higher productivity, as well as, the rate of accumulation of phytomass was growing for the rise in doses of swine manure, with cutting height of $10 \mathrm{~cm}$ showing higher values. The structural characteristics, leaf index and morphological components did not present significant differences for the conditions tested in this work. Thus, the importance of organic fertilization in the pastures of semi-arid regions is verified, constituting a means of increasing the productivity of grasses adapted to the climate, strengthening livestock and reducing expenses.
\end{abstract}

KEYWORDS: Forage, Organic fertilization, Semi-arid, Xerophytic grass. 


\section{INTRODUÇÃO}

0 capim-corrente (Urochloa mosambicensis Hack. Dandy) é originário do continente africano, sendo introduzido no Brasil em 1922 (Puppo, 1979). Esta gramínea perene é adaptada ao clima quente, e apresenta boa tolerância à seca, tendo bom desenvolvimento em regiões com precipitação pluvial média anual de 500 a $1000 \mathrm{~mm}$. O hábito de crescimento desta espécie é bastante variável, sendo comum a presença de estolões ou rizomas, com colmo podendo atingir um metro. São bem aceitos pelos animais, permite pastejo próximo ao nível do solo e pode ser utilizado para produção de feno, no início da floração, devido aos caules tenros e folhas abundantes (Oliveira, 1999). A propagação desta gramínea pode ser realizada via sementes (sexuada) ou por meio de transplantio dos rizomas (assexuada), sendo nesse caso, necessário que o solo apresente alta umidade nos primeiros dias para que ocorra bom pegamento das mudas (Oliveira, 2005).

Resultados demonstraram que a produção de matéria seca do capim-corrente em condição de sequeiro chega a 1.961,4 kg.ha-1, porém com irrigação atingiu 4.350,4 kg.ha-1 no Nordeste brasileiro (Oliveira et al., 2016).

A adubação orgânica quando realizada de forma apropriada pode proporcionar vários benefícios, sendo incremento essencial para o solo $e$, fonte de nutrientes importante para as plantas, ajudando no seu desenvolvimento (Bertol et al., 2010), além disso, a adubação orgânica proporciona melhorias nas propriedades físicas e químicas do solo (Vielmo et al., 2011). Porém, se a adubação com esterco não for realizada de forma apropriada, este produto pode causar vários problemas ambientais, contaminando o solo, animais e fontes de água (Figueiredo et al., 2010). No entanto, poucos são os trabalhos com adubação orgânica em gramíneas forrageiras no bioma Caatinga (Edvan et al., 2010; Primo et al., 2012).

No Semiárido brasileiroé comumà recorrência de longos períodos de estiagens, que por sua vez, afetam de forma negativa a produção animal e toda sua cadeia produtiva. Por isso, fica claro a importância de aprimorar cada vez mais os conhecimentos sobre as espécies forrageiras capazes de suportar esses desafios climáticos. Dessa forma, devido ao potencial forrageiro do capim-corrente em regiões semiáridas e à escassez de informações na literatura, objetivouse avaliar as características estruturais, índice de folhosidade, acúmulo de fitomassa, constituintes morfológicos e taxa de acúmulo de fitomassa desta espécie, adubada com esterco suíno e submetida a duas alturas de corte.

\section{MATERIAL E MÉTODOS}

0 experimento foi realizado na área experimental do Grupo de Estudos em Forragicultura (GEFOR), da Universidade Federal Rural de Pernambuco (UFRPE), Unidade Acadêmica de Serra Talhada (UAST) situada no Semiárido de Pernambuco

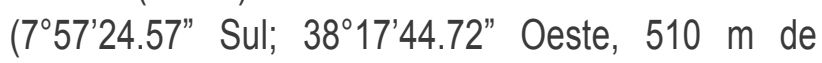
altitude) de abril a setembro de 2016. 0 clima da região é do tipo BSwh' de acordo com a classificação de Köppen, ou seja, semiárido com precipitações pluviais médias anuais em torno de $642 \mathrm{~mm}$, concentradas principalmente nos primeiros quatro meses do ano, temperatura média do ar em torno de $24,8^{\circ} \mathrm{C}$ e umidade relativa do ar em torno de $62,5 \%$ (Silva et al., 2015).

0 delineamento utilizado foi inteiramente casualizado no esquema fatorial $4 \times 2$, com quatro níveis de adubação orgânica $(0,5,10,15$ t.ha-1) e duas alturas de corte $(10$ e $20 \mathrm{~cm})$ do capim-corrente, com três repetições, totalizando 24 parcelas experimentais. Neste ensaio foram utilizados 24 vasos com 6,84 dm3 de solo, todos eles com perfurações no fundo para drenagem da água de irrigação.

Foram coletadas amostras de solo da área experimental de 0 a $20 \mathrm{~cm}$ de profundidade e enviadas para análise no Instituto Agronômico de Pernambuco IPA (Tabela 1).

Tabela 1. Atributos químicos do solo utilizado no experimento

\begin{tabular}{ccccccc}
\hline \multirow{2}{*}{ Amostra } & $\mathrm{Pmg} / \mathrm{dm}^{3}$ & $\mathrm{pH}\left(\mathrm{H}_{2} \mathrm{O}\right)$ & & \multicolumn{3}{c}{$\mathrm{Cmol}_{\mathrm{c}} / \mathrm{dm}^{3}$} \\
\cline { 3 - 6 } & $>40$ & 7,20 & $\mathrm{Kl}^{3+}$ & $\mathrm{Ca}^{2+}$ & \\
\hline $0-20 \mathrm{~cm}$ & & $>0,45$ & 0,00 & 5,30 & 1,10 \\
\hline
\end{tabular}


Inicialmente, foram transplantados dois perfilhos de capim-corrente por vaso, oriundos de área aberta na própria UFRPE. Para evitar condição de estresse hídrico e garantir o bom estabelecimento das plantas, nos primeiros 35 dias após o transplantio, todas as plantas foram mantidas sob condições de capacidade de campo, com base no método gravimétrico, utilizandose balança com precisão de $20,0 \mathrm{~g}$. 0 conteúdo de água no vaso foi controlado diariamente, pelo peso do conjunto vaso + solo + água, repondo-se o volume de água consumido (evapotranspiração) pelo sistema solo planta, conforme Casaroli e Lier (2008). Em sequência, efetuou-se 0 corte de uniformização com alturas de 10 e $20 \mathrm{~cm}$ acima do nível do solo, utilizando tesoura de poda e régua.

Em seguida, o esterco suíno, curtido e seco ao ar livre, adquirido no setor de suinocultura da UAST, foi distribuído sobre a superfície do solo conforme cada tratamento. As doses de esterco suíno utilizadas em cada vaso foram 0, 19, 38 e $57 \mathrm{~g}$, correspondentes a 0, 5, 10 e 15 t.ha $^{-1}$, respectivamente. Após a aplicação do esterco e corte de uniformização, foi realizada a irrigação, mantendo-se o turno de rega de dois dias.

Ao longo do experimento, foram realizadas três colheitas do capim-corrente ao final de cada ciclo produtivo, cortando-se a 10 e $20 \mathrm{~cm}$ acima do nível do solo, conforme cada parcela experimental. A primeira, segunda e terceira colheita foram realizadas aos 60 , 90 e 120 dias após a aplicação de esterco suíno, respectivamente. Imediatamente após a colheita, 0 material vegetal foi pesado em balança semi-analítica e levado para estufa de circulação de ar a $65^{\circ} \pm 5^{\circ} \mathrm{C}$ até atingir massa constante. Depois da secagem, para obtenção da produtividade de matéria seca, considerou-se o material vegetal desidratado total, que foi novamente pesado. Para determinação da taxa de acúmulo de fitomassa (TAF), a matéria seca acumulada durante 0 período de crescimento foi dividida pelo número de dias do ciclo, sendo este procedimento repetido para cada ciclo:

$$
\text { TAF }=\frac{\text { Fitomassa acumulada }}{\text { Número de dias do ciclo) }}
$$

Para a determinação das características estruturais do capim-corrente realizou-se a avaliação de um perfilho por vaso 40 dias após a aplicação do esterco suíno durante o primeiro ciclo. As variáveis observadas foram: diâmetro de colmo (DC), comprimento de colmo $(C C)$, comprimento $(C)$ e largura de lâmina foliar $(L)$, número de folhas vivas (NFV), folhas mortas (NFM) e perfilhos (NP).

Utilizando-se um paquímetro foi medido 0 diâmetro de colmo e largura de lâmina foliar. $\mathrm{O}$ diâmetro de colmo foi medido a 2,0 cm do colo e a largura de lâmina foliar foi considerada a maior medida na região intermediária do limbo. O comprimento de colmo e comprimento de lâmina foliar foi mensurado com auxílio de fita métrica. O comprimento de colmo foi considerado a distância vertical entre a base do colmo até a última lígula completamente expandida e o comprimento da lâmina foliar foi medido ao longo da nervura central, considerando o ponto de inserção do limbo com a lígula até 0 ápice foliar. Na determinação do número de folhas vivas por perfilho foram contabilizadas todas as folhas que apresentaram, no mínimo, $50 \%$ de sua coloração verde, assim como também na determinação das folhas mortas, com a contabilização das folhas que apresentarem menos de $50 \%$ de coloração verde. 0 número de perfilhos foi contabilizado por contagem.

O comprimento e largura da lâmina foliar foram utilizados para o cálculo da área foliar (AF) através do modelo matemático: $\mathrm{AF}=\left(\mathrm{C}^{*} \mathrm{~L}\right)^{0,968}$ (Leite et al., 2017).

A determinação do índice de folhosidade (IF) foi realizada pesando-se separadamente a massa seca de lâmina foliar e colmo, procedendo-se o cálculo que foi definido como o quociente da massa seca de lâmina foliar (MSLF) pela massa seca de colmos (MSC):

$$
\mathrm{IF}=\frac{\mathrm{MSLF}}{\mathrm{MSC}}
$$

A avaliação dos constituintes morfológicos foi realizada após 120 dias da aplicação dos tratamentos, no $3^{0}$ ciclo produtivo do capim-corrente, realizandose a colheita, em que se separou lâmina foliar e pseudocolmo, sendo a lâmina foliar considerada a partir da lígula e o pseudocolmo o conjunto de bainhas foliares. Os dois constituintes foram pesados e, posteriormente, levados à estufa para desidratação a $65^{\circ} \pm 5^{\circ} \mathrm{C}$ até atingir massa constante. Logo após, foram pesados em balança semi-analítica para obtenção de 
massa seca. Após esse procedimento, foi calculada a porcentagem de massa seca de pseudocolmo (PPC) e porcentagem de massa seca de lâmina foliar (PLF).

Os resultados foram expressos por média e desvio padrão. Foi aplicada a análise de variância a fim de comparar as médias das variáveis e posteriormente aplicado o teste de Tukey a $5 \%$ de probabilidade. Foi aplicada a análise de regressão linear simples para saber a relação do acúmulo de fitomassa e taxa de acúmulo de fitomassa em relação aos níveis de esterco suíno e alturas de corte.

\section{RESULTADOS E DISCUSSÃO}

Não houve interação $(p>0,05)$ entre as doses de esterco suíno e as alturas de corte sobre o acúmulo de fitomassa do capim-corrente. As doses mais elevadas de esterco favoreceram o incremento linear crescente da produtividade de fitomassa do capim-corrente. 0 acúmulo de fitomassa para as doses de esterco suíno foi significativa a $1 \%$ de probabilidade na regressão linear, apresentando coeficiente de determinação (R2) de 0,99 para altura de corte de $10 \mathrm{~cm} \mathrm{e} \mathrm{0,94} \mathrm{para} \mathrm{altura}$ de corte de $20 \mathrm{~cm}$. A adubação com 15 t.ha-1 de esterco suíno proporcionou um acúmulo de $3.120,5 \mathrm{~kg} \mathrm{ha}^{-1}$ de matéria seca do capim-corrente na altura de corte de $10 \mathrm{~cm}$, indicando um incremento na matéria seca acumulada de $94,36 \%$ em relação ao tratamento sem adubação orgânica. Quando cortado a $20 \mathrm{~cm}$ do solo, o capim-corrente apresentou produtividade máxima com a dose de 15 tha $^{-1}$ de esterco suíno com acúmulo de 2.448,9 kg.ha-1 de matéria seca, proporcionando incremento de $100,41 \%$ em relação ao tratamento sem adubação orgânica. Quanto às alturas de corte do capim-corrente, observou-se que a altura de 10 $\mathrm{cm}$ apresentou produtividade de fitomassa superior ao corte de $20 \mathrm{~cm}$ de altura. Assim, constata-se que altura de corte mais baixa permitiu produtividade 27,42 \% superior ao corte mais alto (Figura 1). Logo, é possível inferir quão importante é a adubação orgânica em pastagens nas regiões semiáridas, pois, este resultado demonstra a possibilidade de dobrar a produtividade de massa seca das pastagens cultivadas apenas com utilização de esterco suíno, podendo-se dessa forma baratear o custo de produção de forragens no Semiárido brasileiro, uma vez que o esterco pode ser adquirido na própria propriedade ou até mesmo em propriedades vizinhas, evitando-se assim a necessidade de buscar insumos nos centros urbanos. Esses valores de produtividade de fitomassa apresentam-se coerentes com as produtividades citadas por Oliveira et al. (2016) para o capim-corrente no Semiárido brasileiro.

Figura 1. Acúmulo de fitomassa do capim-corrente em função de doses de esterco suíno e alturas de corte.

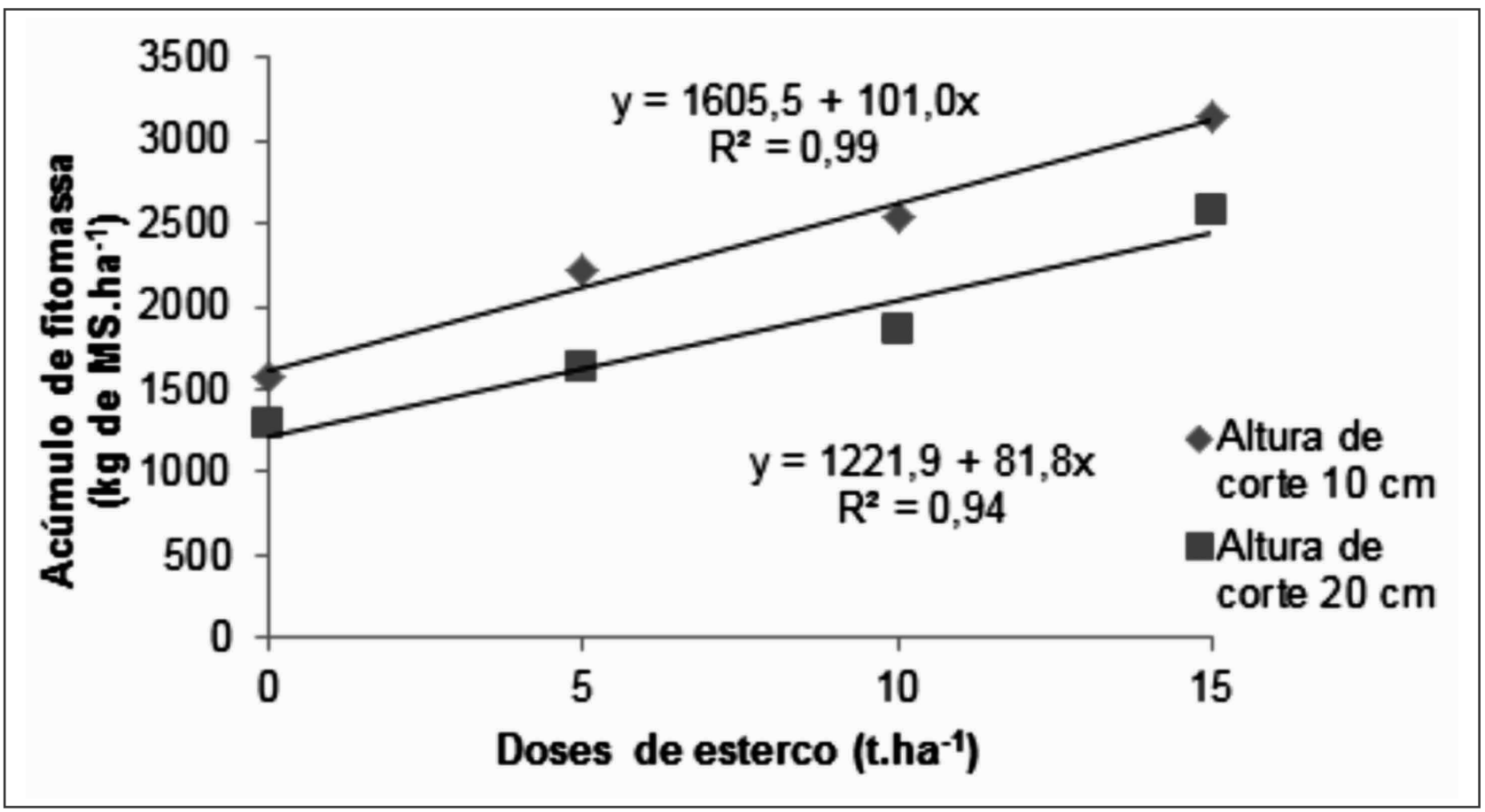


Avaliando-se as taxas de acúmulo de fitomassa do capim-corrente observou-se que, na análise quantitativa, a análise de variância para as doses de esterco foi significativa a $1 \%$ na regressão linear. 0 aumento nas doses de adubação com esterco suíno proporcionou incremento linear crescente da taxa de acúmulo de fitomassa do capim-corrente, com $\mathrm{R}^{2}$ de 0,99 e 0,98 para altura de corte de $10 \mathrm{~cm}$ e $20 \mathrm{~cm}$, respectivamente. Utilizando-se a dose máxima testada com altura de corte de $10 \mathrm{~cm}$ houve um incremento de $62,85 \%$ na taxa de acúmulo de fitomassa do capim-corrente com relação ao tratamento controle, com valores de 30,40 e 18,67 kg de MS.ha-1. dia-1, respectivamente. Quando adubado com 15 t.ha $^{-1}$ de esterco suíno e cortado a $20 \mathrm{~cm}$ do solo, o capim-corrente apresentou taxa de acúmulo de fitomassa de $24,00 \mathrm{~kg}$ de MS.ha ${ }^{-1}$.dia ${ }^{-1}$, sendo $86,81 \%$ superior ao tratamento que não foi adubado. Isso mostra a importância da adubação orgânica em pastagens, constituindo uma forma econômica de aproveitamento dos resíduos da produção de suínos para elevação da produção de fitomassa desta espécie forrageira. É possível, portanto, dar uma destinação correta aos efluentes da suinocultura, convertendo o material poluente em fertilizante orgânico. Comparando-se as taxas de acúmulo de fitomassa do capim-corrente nas alturas de corte de 10 e $20 \mathrm{~cm}$, constata-se que o corte mais próximo ao solo proporcionou um aumento de 33,17 \% em relação ao corte mais alto, com médias de 24,53 e 18,42 kg de MS.ha-1.dia-1, respectivamente. Devido a isso, ressalta-se a necessidade do conhecimento da altura de pastejo ou altura de corte para produção desta espécie, sendo este um fator fundamental para ganhos de produtividade (Figura 2).

Figura 2. Taxa de acúmulo de fitomassa do capim-corrente submetido à adubação com esterco suíno e duas alturas de corte.

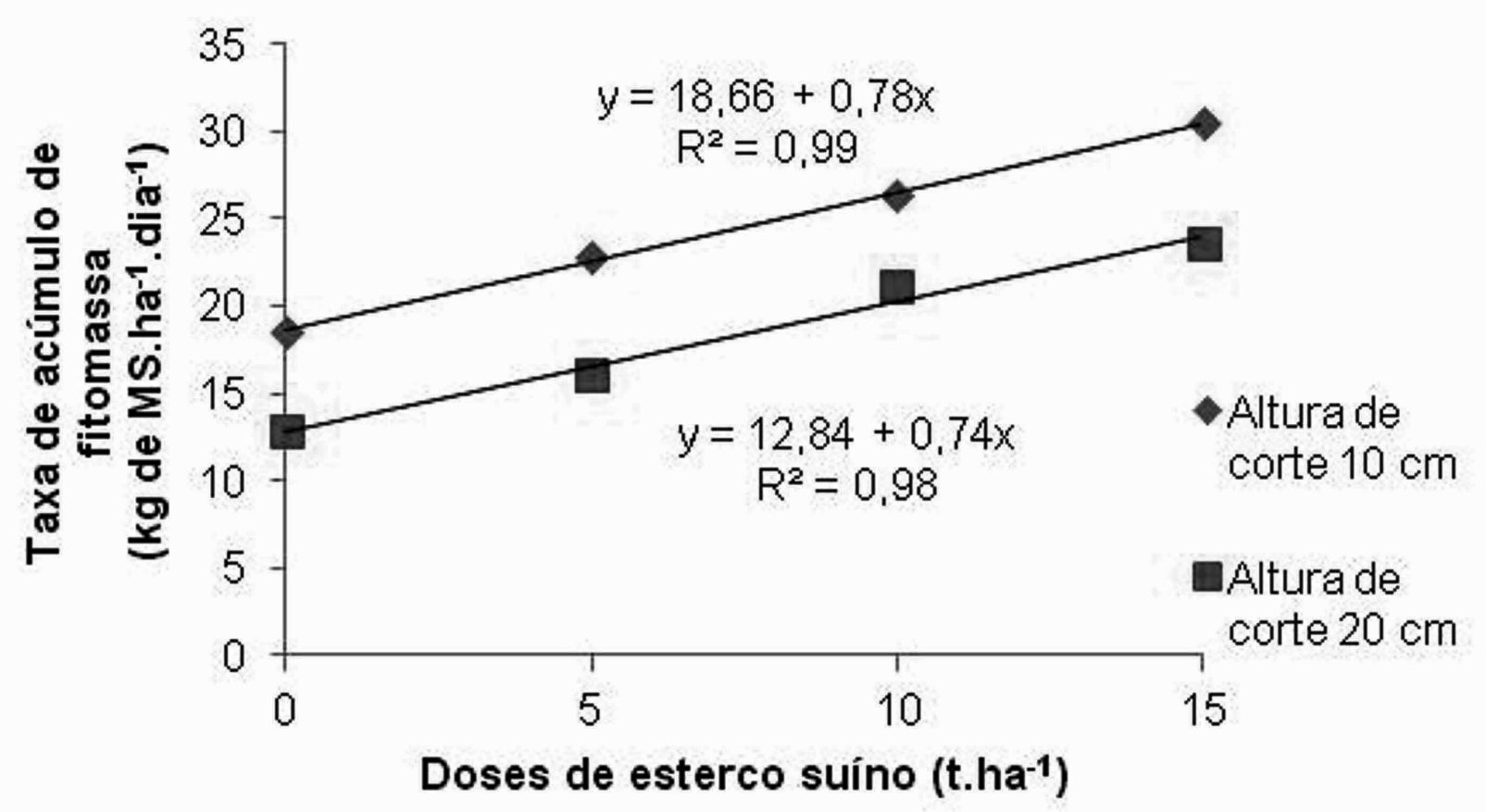

Ao analisar a taxa de acúmulo de fitomassa nos três ciclos separadamente, observa-se que a mesma apresentou diferença significativa entre 0 primeiro, segundo e terceiro ciclo de corte do capimcorrente $(p<0,01)$. A interação das doses de esterco suíno com os três ciclos de corte foi significativa a $1 \%$ de probabilidade no teste $F$. Dessa forma, a taxa de acúmulo de fitomassa do capim-corrente foi maior no primeiro ciclo, intermediária no segundo ciclo e menor no terceiro ciclo produtivo. Isso pode ser explicado devido à adubação orgânica com esterco suíno ter sido realizada apenas no início do primeiro ciclo de produção. Provavelmente, boa parte dos nutrientes foram mineralizados e absorvidos no primeiro ciclo. Camargo etal. (2011), a o analisar a composição química de esterco suíno, encontraram teores de $\mathrm{N}, \mathrm{P}, \mathrm{K}, \mathrm{Ca}$, Mg de 14; 0,78; 1,5; 10 e 2,5 dag. .g $^{-1}$, respectivamente $\mathrm{e}$, os micronutrientes encontrados foram $\mathrm{Cu}, \mathrm{Zn}, \mathrm{Fe}$ e $\mathrm{Mn}$ com teores de 3,9; 3,05; 1,39 e 1,60 mg. $\mathrm{kg}^{-1}$, respectivamente. Isso mostra o potencial de oferta de 
nutrientes do esterco suíno para o desenvolvimento das plantas forrageiras, disponibilizando macro e micronutrientes. Contudo, vale salientar que é necessário repetir a aplicação de esterco após cada corte do capim-corrente, evitando-se assim, aplicar quantidade muito elevada de uma única vez, para que não ocorram impactos ambientais negativos, como por exemplo, contaminação das águas superficiais e subsuperficiais. Observa-se ainda, que em todos os tratamentos do primeiro ciclo houve diferença das médias dos tratamentos nos demais ciclos. No caso da dose de 15 t.ha ${ }^{-1}$ de esterco suíno, a taxa de acúmulo de fitomassa no primeiro ciclo foi de 47,65 kg de MS.ha-1. $\mathrm{dia}^{-1}$, enquanto esta taxa foi de $15,18 \mathrm{~kg}$ de MS.ha- ${ }^{-1}$.dia${ }^{1}$ no último ciclo. Conferindo-se, portanto, uma queda de $68,14 \%$ na taxa de acúmulo de fitomassa do capimcorrente quando comparado o primeiro com 0 último ciclo na dose de 15 t.ha $^{-1}$ (Tabela 2).

Tabela 2. Médias da taxa de acúmulo de fitomassa (TAF) da interação das doses de esterco suíno x ciclos de cortes do capim-corrente

\begin{tabular}{cccc}
\hline \multirow{2}{*}{$\begin{array}{c}\text { Doses de esterco } \\
\text { suíno }\left(\text { t.ha- }{ }^{-}\right)\end{array}$} & \multicolumn{3}{c}{ Taxa de acúmulo de fitomassa $\left(\mathrm{kg}\right.$ de MS.ha ${ }^{-1}$.dia $\left.{ }^{-1}\right)$} \\
\cline { 2 - 4 } & $1^{0}$ Ciclo & $2^{\circ}$ Ciclo & $3^{0}$ Ciclo \\
\hline 0 & $23,77 \mathrm{~A}$ & $11,73 \mathrm{~B}$ & $11,61 \mathrm{~B}$ \\
\hline 5 & $31,98 \mathrm{~A}$ & $14,28 \mathrm{~B}$ & $12,07 \mathrm{~B}$ \\
\hline 10 & $36,53 \mathrm{~A}$ & $21,31 \mathrm{~B}$ & $13,43 \mathrm{C}$ \\
\hline 15 & $47,65 \mathrm{~A}$ & $18,13 \mathrm{~B}$ & $15,18 \mathrm{~B}$ \\
\hline Médias & $34,98 \mathrm{~A}$ & $16,36 \mathrm{~B}$ & $13,07 \mathrm{C}$ \\
\hline
\end{tabular}

Letras iguais na linha não diferem entre si pelo teste Tukey a $5 \%$ de probabilidade.

Após 40 dias da aplicação de esterco suíno $\left(1^{\circ}\right.$ ciclo) não foi verificado diferença $(p>0,05)$ nas características estruturais do capim-corrente nos tratamentos com esterco suíno, como também, não houve interação $(p>0,05)$ entre as doses de esterco suíno e as alturas de corte sobre estas características. As médias de diâmetro de colmo variaram de 2,67 a $3,67 \mathrm{~mm}$, os comprimentos de colmo variaram de 2,67 a 4,67 mm e as áreas foliares oscilaram de 8,68 a 11,24 cm2 (Tabela 3).

Tabela 3. Diâmetro de colmo (DC), comprimento de colmo (CC) e área foliar (AF) do capim-corrente adubado com esterco suíno submetido à altura de corte de 10 e $20 \mathrm{~cm}$

\begin{tabular}{|c|c|c|c|c|c|c|}
\hline \multirow{2}{*}{$\begin{array}{c}\text { Doses de esterco } \\
\left(\text { t.ha }^{-1}\right)\end{array}$} & \multicolumn{3}{|c|}{ Altura de corte $(10 \mathrm{~cm})$} & \multicolumn{3}{|c|}{ Altura de corte $(20 \mathrm{~cm})$} \\
\hline & $\mathrm{DC}(\mathrm{mm})$ & $\mathrm{CC}(\mathrm{cm})$ & $\mathrm{AF}\left(\mathrm{cm}^{2}\right)$ & $\mathrm{DC}(\mathrm{mm})$ & $\mathrm{CC}(\mathrm{cm})$ & $\mathrm{AF}\left(\mathrm{cm}^{2}\right)$ \\
\hline 0 & $3,00 \pm 0,82$ & $4,67 \pm 2,36$ & $9,75 \pm 4,99$ & $2,67 \pm 0,47$ & $3,50 \pm 0$ & $6,73 \pm 0,58$ \\
\hline 5 & $3,17 \pm 0,24$ & $3,63 \pm 0,26$ & $11,24 \pm 3,22$ & $3,33 \pm 0,47$ & $4,50 \pm 0,41$ & $7,96 \pm 0,47$ \\
\hline 10 & $2,67 \pm 0,47$ & $3,17 \pm 1,17$ & $8,68 \pm 3,68$ & $3,00 \pm 0$ & $3,10 \pm 0,65$ & $7,42 \pm 2,57$ \\
\hline 15 & $3,67 \pm 0,47$ & $2,67 \pm 0,94$ & $10,35 \pm 4,69$ & $3,00 \pm 0$ & $4,67 \pm 1,43$ & $9,30 \pm 4,28$ \\
\hline
\end{tabular}

De forma similar, em ensaio que avaliou as características estruturais de Brachiaria decumbens sob diferentes níveis de adução nitrogenada, os autores não verificaram diferença na altura de plantas com 0 aumento das doses de nitrogênio (Alves et al., 2008). Por outro lado, em estudo que avaliou a influência da adubação orgânica na altura de planta de Brachiaria brizantha cv. Marandu foi observado que a altura de planta aumentou quando se utilizou 15 t.ha $^{-1}$ de esterco de galinha. No entanto, quando as doses passaram a ser maiores, a altura de planta foi influenciada de forma negativa, havendo uma redução em sua altura (Silva et al., 2013).

Provavelmente, no presente estudo, as doses de esterco não influenciaram as características estruturais do capim-corrente, aos 40 dias após a adubação, devido ao curto período para mineralização dos nutrientes presentes no esterco. 
Aos 40 dias após a aplicação de esterco suíno ( ${ }^{\circ}$ ciclo) não houve diferença para os tratamentos nem interação entre as fontes de variação $(p>0,05)$ para 0 número de folhas vivas, folhas mortas e perfilhos (Tabela 4). De forma similar, Santos et al. (2011) não verificaram diferenças no número de folhas vivas em Brachiaria decumbens em diferentes alturas de plantas.
Assim como, não foi observado diferença no número de folhas vivas quando compararam o capim-corrente com o capim aruana (Panicum maximum cv. Aruana) e pangolão (Digitaria pentzii), havendo diferença apenas em Brachiaria humidicola que foi superior aos demais (Sousa et al., 2012).

Tabela 4. Número de folhas vivas (NFV), número de folhas mortas (NFM) e número de perfilhos (NP) do capimcorrente adubado com esterco suíno e submetido a duas alturas de corte

\begin{tabular}{|c|c|c|c|c|c|c|}
\hline \multirow{3}{*}{$\begin{array}{c}\text { Doses de esterco } \\
\left(\text { t.ha }^{-1}\right)\end{array}$} & \multicolumn{6}{|c|}{ Altura de corte } \\
\hline & \multicolumn{3}{|c|}{$10 \mathrm{~cm}$} & \multicolumn{3}{|c|}{$20 \mathrm{~cm}$} \\
\hline & NFV & NFM & NP & NFV & NFM & NP \\
\hline 0 & $4,00 \pm 0,82$ & $0,67 \pm 0,47$ & $12,33 \pm 6,18$ & $3,67 \pm 0,94$ & $0,33 \pm 0,47$ & $10,33 \pm 4,92$ \\
\hline 5 & $4,67 \pm 0,94$ & $0,33 \pm 0,47$ & $13,00 \pm 2,16$ & $4,33 \pm 0,94$ & $0,00 \pm 0$ & $8,67 \pm 0,47$ \\
\hline 10 & $3,33 \pm 0,94$ & $0,67 \pm 0,47$ & $11,33 \pm 2,36$ & $4,67 \pm 0,47$ & $0,00 \pm 0$ & $11,33 \pm 3,4$ \\
\hline 15 & $4,00 \pm 0$ & $1,00 \pm 0$ & $16,33 \pm 4,19$ & $4,33 \pm 0,47$ & $1,00 \pm 0,82$ & $10,00 \pm 2,94$ \\
\hline
\end{tabular}

0 índice de folhosidade do capim-corrente oscilou de 2,05 a 3,95, no entanto, não apresentou diferença $(p>0,05)$ em função das doses de esterco. Avaliando-se 0 índice de folhosidade nas duas alturas de corte obteve-se diferença significativa $(p<0,05)$, sendo 3,05 o índice de folhosidade da altura de corte de $20 \mathrm{~cm}$ e 2,23 o índice de folhosidade da altura de corte de $10 \mathrm{~cm}$ (Tabela 5). Assim, verificou-se que as doses de esterco suíno não influenciaram na relação folha:colmo em um único ciclo de crescimento do capim-corrente. Desse modo, o incremento de massa seca das folhas em relação ao colmo manteve-se proporcional, independente das doses de esterco, variando apenas de acordo com a altura de corte.

Tabela 5. Índice de folhosidade do capim-corrente

\begin{tabular}{ccc}
\hline \multirow{2}{*}{ Doses de esterco $\left(\right.$ t.ha $\left.^{-1}\right)$} & \multicolumn{2}{c}{ Altura de corte } \\
\cline { 2 - 3 } & $10 \mathrm{~cm}$ & $20 \mathrm{~cm}$ \\
\hline 0 & 2,33 & 2,45 \\
5 & 2,31 & 2,88 \\
10 & 2,23 & 3,95 \\
15 & 2,05 & 2,93 \\
\hline Médias & $2,23 \mathrm{~B}$ & $3,05 \mathrm{~A}$ \\
\hline
\end{tabular}

Letras iguais na linha não diferem entre si pelo teste Tukey a 5\% de probabilidade.

Em pesquisa realizada com Brachiaria brizantha cv. Xaraés, submetida a doses crescentes de nitrogênio, foi verificado redução na relação folha:colmo a medida em que aumentaram as doses de nitrogênio, provavelmente isso ocorreu devido ao acúmulo de fotoassimilados nos colmos, resultante da adubação nitrogenada (Rodrigues et al. 2008).

A partir dessas análises, observa-se que o presente estudo apresentou altos índices de folhosidade, provavelmente devido à altura de corte e sua frequência. Prova disso são as médias do índice de folhosidade 2,23 e 3,05 para as alturas de corte de $10 \mathrm{~cm}$ e $20 \mathrm{~cm}$, respectivamente. Sendo superior aos poucos resultados encontrados na literatura sobre essa gramínea, em que verificou-se índice de folhosidade de 0,5 (Sousa et al., 2012) e 0,62 (Silva et al., 2011). Portanto, a altura de corte e sua frequência devem ser levados em consideração no planejamento do cultivo de capim-corrente para otimizar sua produtividade. 
$\mathrm{Na}$ avaliação dos constituintes morfológicos do capim-corrente não houve diferença $(p>0,05)$ para os tratamentos com esterco suíno, alturas de corte e interação entre as doses de esterco e altura de corte. A porcentagem de massa seca do pseudocolmo (PPC) na altura de corte de $10 \mathrm{~cm}$ apresentou variações entre 16,55 a $23,5 \%$, e a porcentagem de massa seca de lâmina foliar variou entre 76,41 e $83,45 \%$. Quanto aos constituintes morfológicos do capim-corrente adubado com esterco suíno e submetido à altura de corte de $20 \mathrm{~cm}$ obteve-se porcentagem de massa seca de pseudocolmo de 13,83 a 19,70\%. Enquanto que as porcentagens de massa seca de lâmina foliar apresentaram valor mínimo de $80,30 \%$ e máximo de $86,17 \%$ (Tabela 6). Isso mostra que o capim-corrente possui potencial de manter em níveis elevados a porcentagem da massa de lâminas foliares em relação à porcentagem da massa de pseudocolmo quando cortado em altura mais próxima ao solo, neste caso, em $10 \mathrm{~cm}$. Este comportamento permite inferir que o capimcorrente apresenta boa relação entre a proporção de lâmina foliar em relação à proporção de pseudocolmo, sendo este um fator relevante na qualidade de plantas forrageiras.

Tabela 6. Constituintes morfológicos do capim-corrente: Porcentagem de massa seca de pseudocolmo (PPC) e porcentagem de massa seca de lâmina foliar (PLF) adubado com esterco suíno e submetido a duas alturas de corte

\begin{tabular}{|c|c|c|c|c|}
\hline \multirow{3}{*}{$\begin{array}{c}\text { Doses de } \\
\text { adubação (t.ha-1) }\end{array}$} & \multicolumn{4}{|c|}{ Altura de corte } \\
\hline & \multicolumn{2}{|c|}{$10 \mathrm{~cm}$} & \multicolumn{2}{|c|}{$20 \mathrm{~cm}$} \\
\hline & PPC (\%) & PLF (\%) & PPC (\%) & PLF (\%) \\
\hline 0 & 16,55 & 83,45 & 13,83 & 86,17 \\
\hline 5 & 17,02 & 82,98 & 16,54 & 83,46 \\
\hline 10 & 23,59 & 76,41 & 19,70 & 80,30 \\
\hline 15 & 17,27 & 82,73 & 16,06 & 83,94 \\
\hline
\end{tabular}

O acúmulo de fitomassa e taxa de acúmulo de fitomassa apresentam resposta linear crescente com relação ao incremento das doses de esterco suíno, sendo a altura de corte de $10 \mathrm{~cm}$ responsável por maior produtividade de matéria seca. Assim, constatase a importância da adubação orgânica nas pastagens de regiões semiáridas, constituindo-se uma estratégia para aumentar a produtividade de fitomassa de gramíneas adaptadas ao clima, fortalecendo a pecuária e reduzindo custos.

\section{REFERÊNCIAS BIBLIOGRÁFICAS}

Alves, J.S.; Pires, A.J.V.; Matsumoto, S.N.; Figueiredo, M.P.; Ribeiro, G.S.; Características morfológicas e estruturais da Brachiaria decumbens Stapf. submetida a diferentes doses de nitrogênio e volumes de água. Acta Veterinaria Brasilica. 2008, 2, 1, 1-10.

Bertol, O.J.; Fey, E.; Favaretto, N.; Lavoranti, E. J.; Rizzi, N.E. Mobilidade de P, Cu e Zn em colunas de solo sob sistema de semeadura direta submetido às adubações mineral e orgânica. Revista Brasileira de Ciência do Solo. 2010, 34, 1841-1850.

Camargo, S. C.; Mesquita, E. E.; Castagnara, D. D.; Neres, M. A.; Oliveira, P. S. R. Efeito da aplicação de dejetos de suínos na concentração de minerais na parte aérea de capins Tifton 85. Scientia Agraria Paranaenis. 2011, 10, 2, 51-62.

Casaroli, D.; Lier, Q.J.V. Critérios para determinação da capacidade de vaso. Revista Brasileira de Ciência do Solo. 2008, 32, 1, 59-66.

Edvan, R.L.; Santos E.M.; Vasconcelos, W.A.; Souto filho, L.T.; Borburema, J.B.; Medeiros, G.R.; Andrade, A.P. Utilização de adubação orgânica em pastagem de capim-buffel (Cenchrus ciliaris cv. Molopo). Archivos de Zootecnia. 2010, 59, 228, 499-508.

Figueiredo, P.G.; Tanamati, F.Y. Adubação orgânica e contaminação ambiental. Revista Verde de Agroecologia e Desenvolvimento Sustentável. Grupo verde de Agricultura Alternativa. 2010, 5, 3, 01-04. 
Leite, M.L.M.V; Lucena, L.R.R.; Sá Júnior, E.H.; Cruz, M.G. Estimativa da área foliar em Urochloa mosambicensis por dimensões lineares. Revista Agropecuária Técnica. 2017, 38, 1, 9-16.

Oliveira, M.C. Capim urocloa: produção e manejo no semi-árido do Nordeste do Brasil. Petrolina, PE: EMBRAPA-CPATSA, 1999. 20p. (EMBRAPA-CPATSA. Circular Técnica, 43).

Oliveira, M.C. Capim-urocloa. In: Kiill, L.H.P.; Menezes, E.A. Espécies Vegetais Exóticas com Potencialidades para o Semi-Árido Brasileiro. Brasília: Embrapa Semiárido. 2005, 206-225.

Oliveira, V.S.; Santana, J.C.S.; Morais, J.A.S.; Santos, C.B.; Lima, I.G.S. Capacidade de suporte, produção e composição do dossel forrageiro de três gramíneas irrigadas ou não no período seco. Veterinária e Zootecnia. 2016, 23, 1, 88-92.

Primo, D.C.; Menezes, R.S.C.; Silva, T.O.; Garrido, M.S.; Cabral, P.K.T. Contribuição da adubação orgânica na absorção de nutrientes e na produtividade de milho no semiárido paraibano. Revista Brasileira de Ciências Agrárias. 2012, 7, 1, 81-88.

Puppo, N.I.H. Manual de pastagens e forrageiras: formação, conservação, utilização. Instituto Campineiro de Ensino Agrícola. Campinas, SP. p. 343. 1979.

Rodrigues, R.C.; Mourão, G.B.; Brenneceke, K.; Luz, P.H.C.; Herling, V.R. Produção de massa seca, relação folha/colmo e alguns índices de crescimento do Brachiaria brizantha cv. Xaraés cultivado com a combinação de doses de nitrogênio e potássio. Revista Brasileira de Zootecnia. 2008, 37, 3, 394-400.
Santos, M.E.R; Fonseca, D.M.; Braz, T.G.S.; Silva, S.P.; Gomes, V.M.; Silva, G.P. Características morfogênicas e estruturais de perfilhos de capim-braquiária em locais do pasto com alturas variáveis. Revista Brasileira de Zootecnia. 2011, 40, 3, 535-542.

Silva, E.B.; Carneiro, M.S.S.; Edvan, R.L.; Coutinho, M.J.F.; Rodrigues Júnior, C.T.; Silva, M.S.M. Componentes morfológicos e curva de desidratação de gramíneas tropicais. Tecnologia \& Ciência Agropecuária. 2011, 5, 3, 43-46.

Silva, A.A.; Simioni, G.F.; Lucena, A. Efeito da adubação orgânica no crescimento do capim Brachiaria brizantha cV. marandu em Parecis/Rondônia. Enciclopédia Biosfera, Centro Científico Conhecer. 2013, 9, 16, 923.

Silva, T.G.F.; Araújo Primo, J.T.; Moura, M.S.B.; Silva, S.M.S.; Morais, J.E.F.; Pereira, P.C.; Souza, C.A.A. Soil water dynamics and evapotranspiration of forage cactus clones under rainfed conditions. Pesquisa Agropecuária Brasileira. 2015, 50, 7, 515-525.

Sousa, R.A.; Fontes, J.G.G.; Melo, Y.C.L.; Moreira, J.A.S.; Santos, I.O.G.; Sanzio, E.C.; Barbosa, L.T.; Fagundes, J.L. Características Estruturais de Gramíneas Tropicais na Região dos Tabuleiros Costeiros Sergipanos. Revista Cientifica de Produção Animal. 2012, 14, 1, 17-20.

Vielmo, H.; Bona Filho, A.; Soares, A.B.; Assmann, T.S.; Adami, P.F. Effect of fertilization with fluids wines lurry on production and nutritive value of Tifton 85 . Revista Brasileira de Zootecnia. 2011, 40, 1, 60-68. 